\title{
Incidence of spine fracture hospitalization and surgery in Finland in 1998-2017
}

Ville T. Ponkilainen, $\mathrm{MD}^{1}$; Leevi Toivonen, $\mathrm{MD}^{1}$; Seppo Niemi ${ }^{2}$; Pekka Kannus, $\mathrm{MD}, \mathrm{PhD}^{1}$;

Tuomas T. Huttunen, $\mathrm{MD}, \mathrm{PhD}^{3,4,5}$; Ville M. Mattila, $\mathrm{MD}, \mathrm{PhD}^{1,3,6}$

\section{Authors’ Affiliations:}

${ }^{1}$ Department of Orthopaedics and Traumatology, Tampere University Hospital, Finland

${ }^{2}$ Injury \& Osteoporosis Research Center, UKK Institute, Tampere, Finland

${ }^{3}$ Faculty of Medicine and Health Technology, Tampere University, Tampere, Finland

${ }^{4}$ Department of Emergency, Anesthesia and Pain Medicine, Tampere University Hospital, Finland

${ }^{5}$ The Division of Orthopedics and Biotechnology, Department of Clinical Science, Intervention and

Technology (CLINTEC), Karolinska Institutet, Stockholm, Sweden

${ }^{6}$ COXA Hospital for Joint Replacement, Biokatu 6, 33520 Tampere, Finland

\section{Funding}

This study did not receive funding from any organization.

\section{Corresponding author:}

Ville T. Ponkilainen, MD

Department of Orthopaedics and Traumatology, Tampere University Hospital, Teiskontie 35, PL2000, 33521 Tampere, Finland

Email: ville.ponkilainen@tuni.fi

Phone: +358405139729

\begin{abstract}
Study Design: Retrospective cohort study

Objective: The aim of this study was to assess the incidence and trends of the spine fracture hospitalization and surgery in Finland in 1998-2017.
\end{abstract}


Summary of Background Data: Traumatic spine fractures are rare, yet they are known to cause significant long-term disability and therefore social, functional and financial burden. The incidence of spine fractures and related mortality has been suggested to have declined during recent years. However, there are no population-based studies investigating the incidence of surgical treatment of spine fractures.

Methods: The data for this study was obtained from the Finnish nationwide National Hospital Discharge Register. The study population covered all patients 20 years of age or over in Finland during a 20-year period from 1 January 1998 to 31 December 2017.

Results: A total of 54,612 patients were hospitalized for a spine fracture in Finland in 1998-2017, and 7,138 (13\%) of the patients underwent surgery. The annual population-based incidence of spine fracture hospitalization increased 57\% during the 20-year period, from 57 per 100,000 person-years to 89 per 100,000 person-years. In addition, the incidence of spine fracture surgery increased 65\%, from 5.3 per 100,000 person-years to 8.8 per 100,000 person-years. The incidence of cervical spine fracture surgery tripled, and thoracic spine surgery doubled from 1998 to 2017, while incidence of lumbar fracture surgery declined by $13 \%$. Among patients 60 years of age or older, the incidence of cervical spine fracture surgery increased $400 \%$.

Conclusions: Incidences of cervical, thoracic and lumbar fracture hospitalizations increased constantly in Finland during 1998-2017. Correspondingly, incidence of cervical and thoracic spine fracture surgery increased rapidly, whereas the incidence of lumbar fracture surgery even decreased, during this 20-year period.

Key Words: Spine; fracture; hospitalization; surgery; incidence; epidemiology

\section{Mini Abstract}

The aim was to assess the incidence and trends of the spine fracture hospitalization and surgery in Finland in 1998-2017. The incidence of cervical spine fracture surgery tripled, and thoracic spine 
surgery doubled, and the incidence of cervical spine fracture surgery increased $400 \%$ among patients aged over 60 years.

\section{Key Points}

- $\quad$ The annual population-based incidence of spine fracture hospitalization increased 57\% during the 20-year period, from 57 per 100,000 person-years to 89 per 100,000 personyears.

- The incidence of cervical spine fracture surgery tripled, and thoracic spine surgery doubled from 1998 to 2017.

- Among patients 60 years of age or older, the incidence of cervical spine fracture surgery increased $400 \%$.

\section{Introduction}

Traumatic spine fractures are uncommon fractures, accounting for only $0.7 \%$ of all fractures among adult patients ${ }^{1}$. Although these injuries are rare, they are known to cause significant long-term disability ${ }^{2}$ and socioeconomic burden ${ }^{3}$.

Incidence of spine fracture hospitalization has previously been between 26 and 27 per 100,000 person-years in Finland ${ }^{4,5}$, whereas in other nations these numbers have been reported to be between 16 and $64^{6,7}$. In the USA, the prevalence of any spine fracture has been estimated to be $5 \%$ in persons under 60 years of age and rise up to $18 \%$ in persons 80 years of age and over ${ }^{8}$.

The incidence of spine fracture is known to increase with age, rising tendency to fall, and reduced bone density ${ }^{7-14}$. Osteoporotic compression fractures occur annually in $1.1 \%$ of women and $0.6 \%$ of men between 50 and 79 years of age ${ }^{10}$.

The most common trauma mechanism of spine fracture is an accidental fall, while 
injuries related to traffic collisions are the most common mechanism among younger male patients $^{2,4,7,15}$. Majority of the spinal fractures affect the cervical spine (60\%), whereas the lumbar (25\%) and thoracic (11\%) injuries are less common ${ }^{15}$.

Spinal cord injury (SCI) is an undesirable outcome affecting up to $20 \%$ of patients with spinal fractures ${ }^{2}$. There is a general consensus that patients with a clearly unstable spine fracture with or without SCI will benefit from surgical treatment ${ }^{16}$. The role of surgery in thoracolumbar burst fractures without neurologic or posterior band injuries is unknown ${ }^{16}$. A Cochrane systematic review and meta-analysis from 2013 found no difference between operative and conservative treatment of burst fractures, although the evidence was based on two small and unfortunately biased randomized controlled trials only ${ }^{17}$.

According to previous epidemiological studies from Finland, the incidence of fallrelated cervical spine injuries has risen rapidly among older individuals ${ }^{18-20}$. However, it is unknown whether the rising incidence of cervical fractures has affected the trend in cervical fracture surgery. Also, the incidence trends of spine fractures in general including fracture surgery are yet unclear. The aim of this study was thus to assess the incidence and trends of the spine fracture hospitalization and surgery in Finland in 1998-2017.

\section{Materials and Methods}

Patient data was obtained from the Finnish National Hospital Discharge Register (NHDR) between January $1^{\text {st }} 1998$ and December $31^{\text {st }} 2017$. All patients 20 years of age or older were included into the study. Patient characteristics, such as age, sex, domicile of the subject, hospital stay duration, primary and secondary diagnoses, and operations performed during the hospital stay, were obtained from the Finnish NHDR. All Finnish hospitals are required to collect the data to NHDR, and the quality of the database has been shown to be excellent regard to coverage and accuracy ${ }^{21-23}$. However, the NHDR does not include reliable data on co-morbidities and other risk factors. 
Patients were selected using the diagnoses with codes of the International Classification of Diseases, Tenth Revision (ICD-10): S12.0 (Fracture of first cervical vertebra), S12.1 (Fracture of second cervical vertebra), S12.2 (Fracture of other specified cervical vertebra), S12.7 (Multiple fractures of cervical spine), S22.0 (Fracture of thoracic vertebra), S22.1 (Multiple fractures of thoracic spine), S32.0 (Fracture of lumbar vertebra), S32.1 (Fracture of sacrum), S32.7 (Multiple fractures of lumbar spine and pelvis). Patients who underwent surgery were identified by NOMESCO (Nordic Medico-Statistical Committee) classification procedure codes: NAJ00 (Closed reduction of fracture of spine), NAJ10 (Anterior reduction of fracture of cervical spine), NAJ12 (Posterior reduction of fracture of cervical spine), NAJ20 (Anterior reduction of fracture of thoracic spine), NAJ22 (Posterior reduction of fracture of thoracic spine), NAJ30 (Anterior reduction of fracture of lumbar spine), NAJ32 (Posterior reduction of fracture of lumbar spine) and NAJ99 (Other fracture operations of spine). In addition, all spine fusion operations (NAG40-NAG99) with spine fracture diagnosis were included.

\section{Statistical analysis}

The incidence rates were calculated from annual mid-populations, which were obtained from our national computer-based population register: The Official Statistics of Finland. The incidence rates (per 100,000 persons) were not cohort-based estimates but true final results from the entire adult population of Finland (5.1 million in 1998, and 5.5 million in 2017), and, the subgroup analyses were conducted by calculating the annual incidences for the distinct age and gender population. Statistical analysis was performed using SPSS $@$ (version 24) and Microsoft Excel (version 16). 


\section{Results}

A total of 54,612 patients were hospitalized with a spine fracture diagnosis in Finland between 1998 and 2017. Altogether 7,138 (13\%) of these patients underwent surgery. The annual populationbased incidence of spine fracture hospitalization increased $57 \%$ during the 20 -year period, from 57 per 100,000 person-years in 1998 to 89 per 100,000 person-years in 2017 (Figure 1).

During the study period, the incidence of spine fracture surgery increased 65\%, from 5.3 per 100,000 person-years in 1998 to 8.8 per 100,000 person-years in 2017 (Figure 1). Despite the increased incidence of lumbar spine fractures (from 34 to 52 per 100,000 person-years), the incidence of lumbar spine fracture surgery decreased by $13 \%$ by time, from the most common spine fracture surgery (2.7 per 100,000 person-years) in 1998 to least common surgery in 2017 (2.4 per 100,000 person-years) (Figure 2A and B). Additionally, the surgical rate of lumbar fractures dropped from $8.0 \%$ to $4.6 \%$ (Table 1 ).

During the study period, the incidence of cervical spine fractures increased (from 7.7 to 17 per 100,000 person-years) with $186 \%$ rise in the incidence of cervical spine fracture surgery (from 1.4 to 4.1 per 100,000 person-years) (Figure 2A and B). This surgery became the most common spine fracture surgery after the year 2006. The surgical rate of cervical fractures increased from 18.9\% to 24.3\% between 1998 and 2017 (Table 1).

The incidence of thoracic spine fracture surgery increased $97 \%$, from 1.2 to 2.3 per 100,000 person-years in 1998-2017 (Figure 2A and B), and simultaneously the overall surgical rate of thoracic fractures increased from $7.7 \%$ to $11.3 \%$ (Table 1 ).

The incidence of spine fracture surgery rose among both genders, $72 \%$ among men and 48\% among women (Figure $3 \mathrm{~A}$ and $\mathrm{B}$ ). The incidence of lumbar fracture surgery decreased 19\% among men and 5\% among women, whereas the incidence of cervical fracture surgery increased $196 \%$ among men and 147\% among women. The incidence of thoracic spine fracture surgery increased 94\% in men and 100\% in women (Figure 3 A and B). 
The incidence of cervical spine surgery rose $400 \%$ among patients 60 years of age or older, from 1.7 per 100,000 person-years in 1998 to 8.5 per 100,000 person-years in 2017 (Figure 4). Also, the incidence of thoracic or lumbar fracture surgery increased among these patients, while the surgical incidence rates among younger patients did not show consistent trend changes in 19982017 (Figures 5 and 6).

\section{Discussion}

To the best of our knowledge, this is the first study describing the population-based incidence of spine fractures and spine fracture surgery. The main finding of this study was that the incidence of spine fracture hospitalization in Finland rose 57\%, and the incidence of spine fracture surgery 65\%, during the 20-year time period between 1998 and 2017. The increase in spine fracture incidence was mostly caused by rapid increase in lumbar spine fractures after year 2009 and by more constant increase in cervical and thoracic fractures.

The incidences of spine fracture surgeries did not consistently follow the trends of the spine fracture incidences: The surgical rate of lumbar spine fractures decreased from $8.0 \%$ to $4.6 \%$, while the surgical rate of cervical spine fractures increased from $18.9 \%$ to $24.3 \%$ and that of the thoracic spine fractures from $7.7 \%$ to $11.3 \%$. Thus, despite the notable increase in incidence of lumbar fractures, its surgery incidence decreased, and conversely, the incidence of cervical and thoracic spine surgeries rose more clearly than that of the cervical and thoracic fractures.

The rapidly rising incidence of fall-related cervical traumas of older adults has been reported in the previous studies from Finland ${ }^{18-20}$. The incidence has been rising slowly from 1970 until year 2000, and thereafter the incidence has rapidly increased till the year $2011^{18-20}$. Similar trends have been reported from Sweden ${ }^{24}$, USA ${ }^{25}$ and Iceland ${ }^{26}$. Korhonen and colleagues (2014) predicted that the incidence of fall-induced cervical spine injuries would increase by $50 \%$ between 2011 and 2030. Similar to these previous findings, we found a rising incidence of cervical spine 
fractures. Furthermore, we found that the increase in the cervical spine fracture surgery was almost two thirds higher than the increase in cervical spine fractures. The increase in the surgical treatment was most remarkable among patients over 60 years: the surgery incidence increased by $400 \%$ among this distinct age group, whereas the increase was $15 \%$ and $47 \%$ among the younger age groups. Similar trends were noted in thoracic spine fractures: the increase in surgery incidence was more than two times higher than the increase in the fracture incidence.

Jansson et al. (2010) ${ }^{27}$ investigated the incidence of thoracolumbar fractures and fracture surgery in Sweden. Surprisingly, their data showed that the number of fractures increased between 1997 and 2001, but the number of fracture surgeries decreased among patients under 60 years of age. In contrast, the Swedish trends were opposite among patients over 60 years. Also, in our study the increase in surgery incidence was the highest in patients over 60 years. It is possible that the main reason for the increased spine fracture incidence is the increasing prevalence of osteoporotic fractures in the growing older population. In addition, the better availability and increased use of computed tomography makes it possible to detect more subtle fractures, that are mainly stable. This may also explain the tendency towards non-operative treatment in lumbar spine fractures.

There is tendency towards more active operative management of cervical fractures. This phenomenon is seen in other fields of traumatology too, where novel implants and evolving operating techniques become available ${ }^{28-32}$. However, this study cannot answer the question whether the proportion of clearly unstable fractures has increased in line with the rising frequency of surgical treatment. Fractures in ankylosed spine are considered very unstable and therefore neurologically risky and are usually operated with long constructs ${ }^{33,34}$. These fractures often occur in older population along with the progress of the ankylosing process ${ }^{34-37}$. Also, high energy fractures might be increasing in elderly people, since many people stay active longer in older age. A spine fracture results in hospitalization period in Finland due to pain and disability 
and for setting a diagnosis. We are not aware of any changes in the threshold of hospitalization or in clinical practice during our study period 1998-2017, and thus, the trends observed in the fracture incidences should not be affected by altered indications for hospital care.

The strength of this study is the nationwide register-based data, which have shown to be complete and accurate for epidemiologic purposes ${ }^{21-23}$. The limitation of this study is that the data regarding spine fracture incidences were obtained from a NHDR, which contains data from patients treated in hospital departments only. Therefore, minor fractures (such as benign osteoporotic compressions) that did not require hospital treatment were not included in the study. However, we can assume that a great majority of the true spine fractures were treated in hospitals, and therefore, the number of neglected patients was relatively low. A second limitation was that ICD-10 coding has some limitations concerning multi-traumas or fractures in the spine and pelvis. This may have caused a slight underestimation of the true fracture incidence.

\section{Conclusions}

In conclusion, the incidence of spine fracture hospitalization and surgery has risen remarkably in Finland between 1998 and 2017. The increasing spine fracture incidence was mostly caused by a rapid increase in lumbar spine fractures after year 2009 and by a constant, more steady increase in cervical and thoracic fractures. Despite the notable increase in the lumbar fractures, its surgery incidence decreased, and conversely, the incidence of cervical and thoracic spine fracture rose with even more deeply risen incidence of cervical and thoracic fracture surgery. The reasons for the observed changes are largely unknown and open to discussion, speculations and further studies. 
226 Table 1. The incidence of hospitalization and surgery of spine fracture in Finland in 1998-2017

\begin{tabular}{|c|c|c|c|c|c|c|c|c|c|}
\hline \multirow[b]{2}{*}{$\underline{\text { Year }}$} & \multicolumn{3}{|c|}{ Incidence of hospitalization } & \multicolumn{3}{|c|}{ Incidence of surgery } & \multicolumn{3}{|c|}{ Surgery rate } \\
\hline & Cervical & Thoracic & Lumbar & Cervical & Thoracic & Lumbar & Cervical & Thoracic & Lumbar \\
\hline 1998 & 7.7 & 15.2 & 34.0 & 1.4 & 1.2 & 2.7 & $18.9 \%$ & $7.7 \%$ & $8.0 \%$ \\
\hline 1999 & 8.1 & 14.2 & 32.5 & 1.6 & 1.5 & 3.5 & $20.1 \%$ & $10.5 \%$ & $10.8 \%$ \\
\hline 2000 & 8.5 & 15.4 & 32.7 & 2.2 & 1.7 & 3.0 & $26.1 \%$ & $10.9 \%$ & $9.2 \%$ \\
\hline 2001 & 9.8 & 14.7 & 32.4 & 2.4 & 1.6 & 3.0 & $24.8 \%$ & $10.6 \%$ & $9.3 \%$ \\
\hline 2002 & 9.8 & 13.7 & 33.6 & 2.2 & 1.4 & 3.3 & $22.9 \%$ & $10.5 \%$ & $9.7 \%$ \\
\hline 2003 & 9.6 & 15.3 & 32.0 & 2.7 & 2.1 & 4.0 & $28.3 \%$ & $13.8 \%$ & $12.4 \%$ \\
\hline 2004 & 10.8 & 15.8 & 33.1 & 2.7 & 2.0 & 3.9 & $24.7 \%$ & $12.7 \%$ & $11.7 \%$ \\
\hline 2005 & 12.9 & 14.5 & 32.6 & 2.8 & 1.9 & 3.2 & $21.3 \%$ & $12.9 \%$ & $9.9 \%$ \\
\hline 2006 & 12.7 & 14.3 & 31.9 & 2.9 & 1.6 & 3.0 & $23.2 \%$ & $10.9 \%$ & $9.3 \%$ \\
\hline 2007 & 14.1 & 16.1 & 31.9 & 3.5 & 2.2 & 3.4 & $24.7 \%$ & $13.7 \%$ & $10.6 \%$ \\
\hline 2008 & 13.6 & 16.1 & 34.2 & 3.4 & 2.2 & 2.9 & $24.7 \%$ & $13.9 \%$ & $8.4 \%$ \\
\hline 2009 & 14.0 & 15.8 & 33.1 & 3.9 & 2.0 & 3.1 & $28.2 \%$ & $12.5 \%$ & $9.2 \%$ \\
\hline 2010 & 15.3 & 15.1 & 34.9 & 4.3 & 2.4 & 3.7 & $28.0 \%$ & $15.8 \%$ & $10.5 \%$ \\
\hline 2011 & 16.4 & 15.2 & 34.4 & 4.7 & 2.3 & 3.3 & $29.0 \%$ & $14.8 \%$ & $9.6 \%$ \\
\hline 2012 & 16.9 & 16.2 & 36.6 & 4.5 & 2.9 & 3.1 & $26.7 \%$ & $17.6 \%$ & $8.5 \%$ \\
\hline 2013 & 16.8 & 18.2 & 42.1 & 4.4 & 2.5 & 3.3 & $26.5 \%$ & $13.5 \%$ & $7.7 \%$ \\
\hline 2014 & 18.7 & 18.7 & 47.6 & 5.1 & 2.5 & 3.2 & $27.2 \%$ & $13.4 \%$ & $6.7 \%$ \\
\hline 2015 & 17.2 & 20.2 & 47.2 & 4.3 & 2.5 & 3.5 & $24.8 \%$ & $12.3 \%$ & $7.4 \%$ \\
\hline 2016 & 18.9 & 18.0 & 49.5 & 5.3 & 2.7 & 2.7 & $27.9 \%$ & $14.8 \%$ & $5.5 \%$ \\
\hline 2017 & 17.1 & 20.3 & 51.6 & 4.1 & 2.3 & 2.4 & $24.3 \%$ & $11.3 \%$ & $4.6 \%$ \\
\hline
\end{tabular}




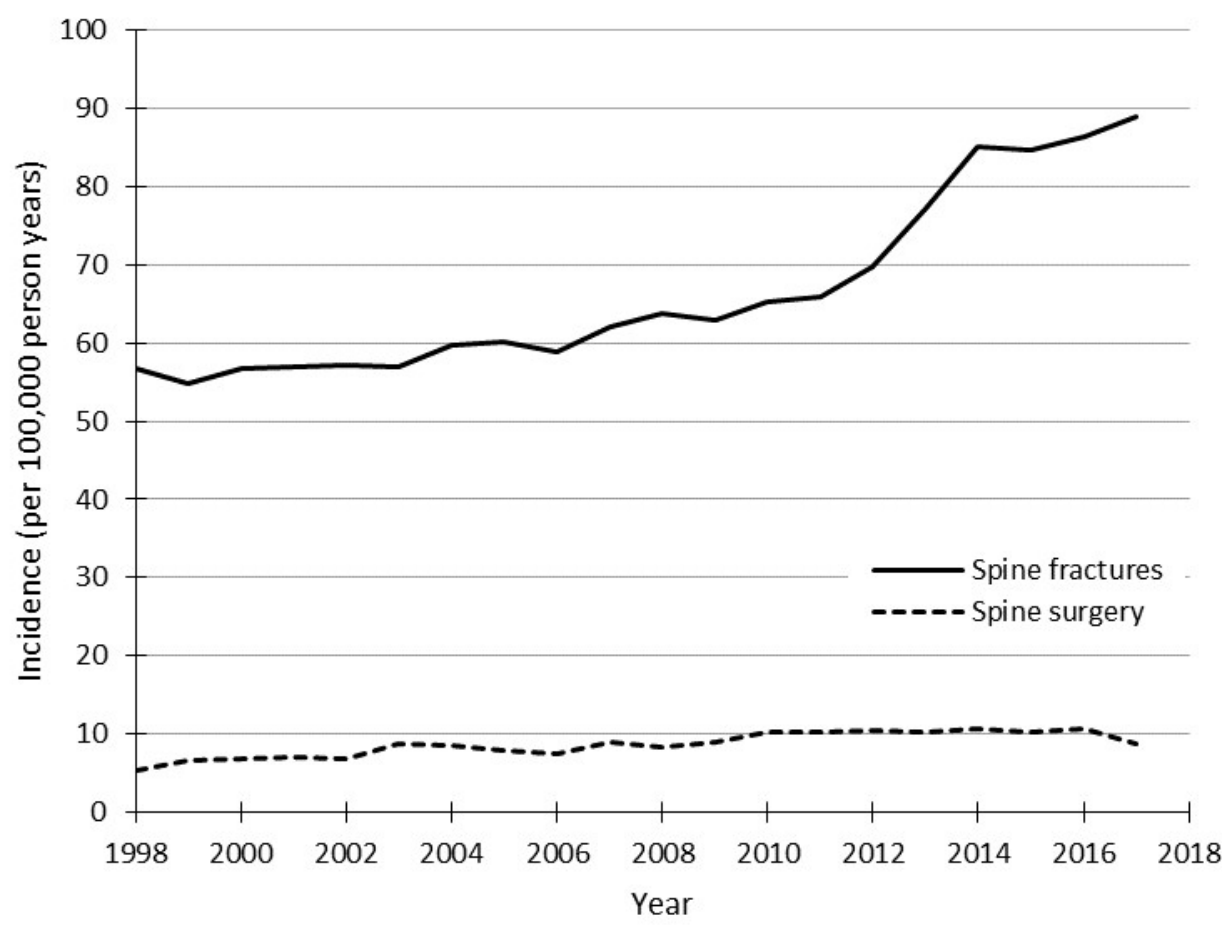

249 Figure 1. The incidence of spine fracture hospitalizations and spine fracture surgery in Finland 250 between 1998 and 2017.

251 

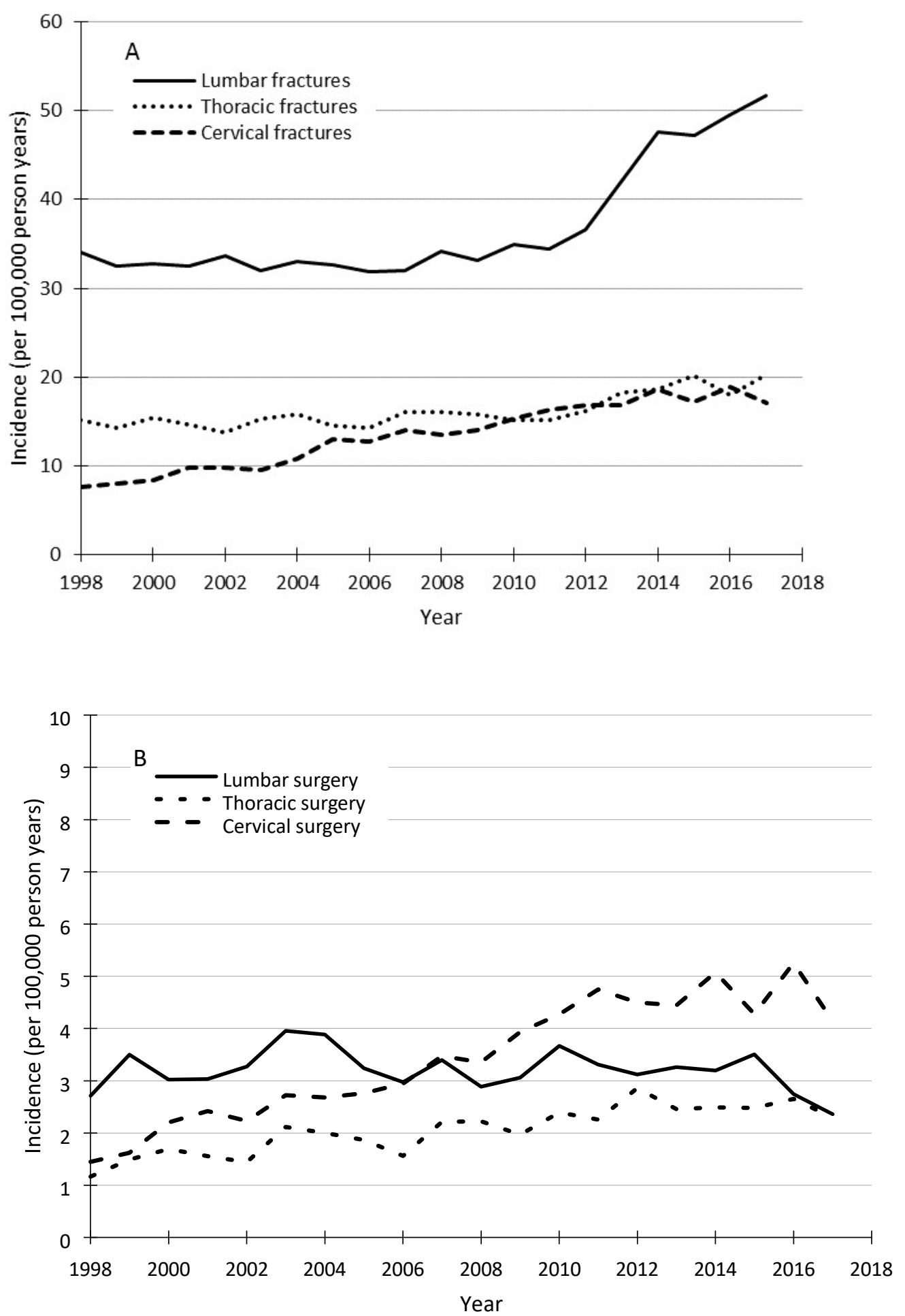

Figure 2A-B. The incidence of spine fracture hospitalizations (A) and spine fracture surgery

(B) in $274 \quad$ Finland between 1998 and 2017. 

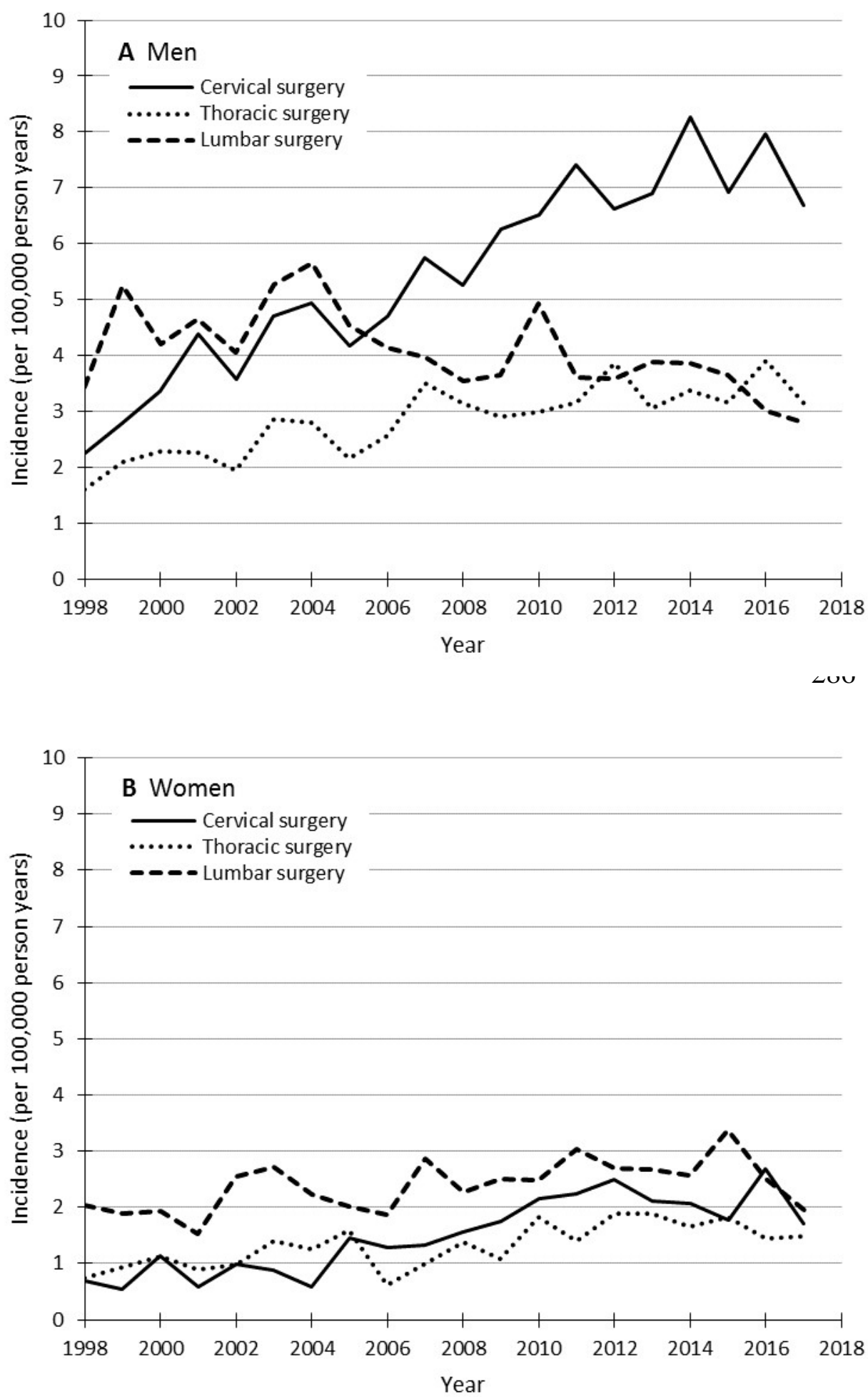

Figure 3A-B. The incidence of spine fracture surgery in Finnish men (A) and women (B) between 2981998 and 2017 . 


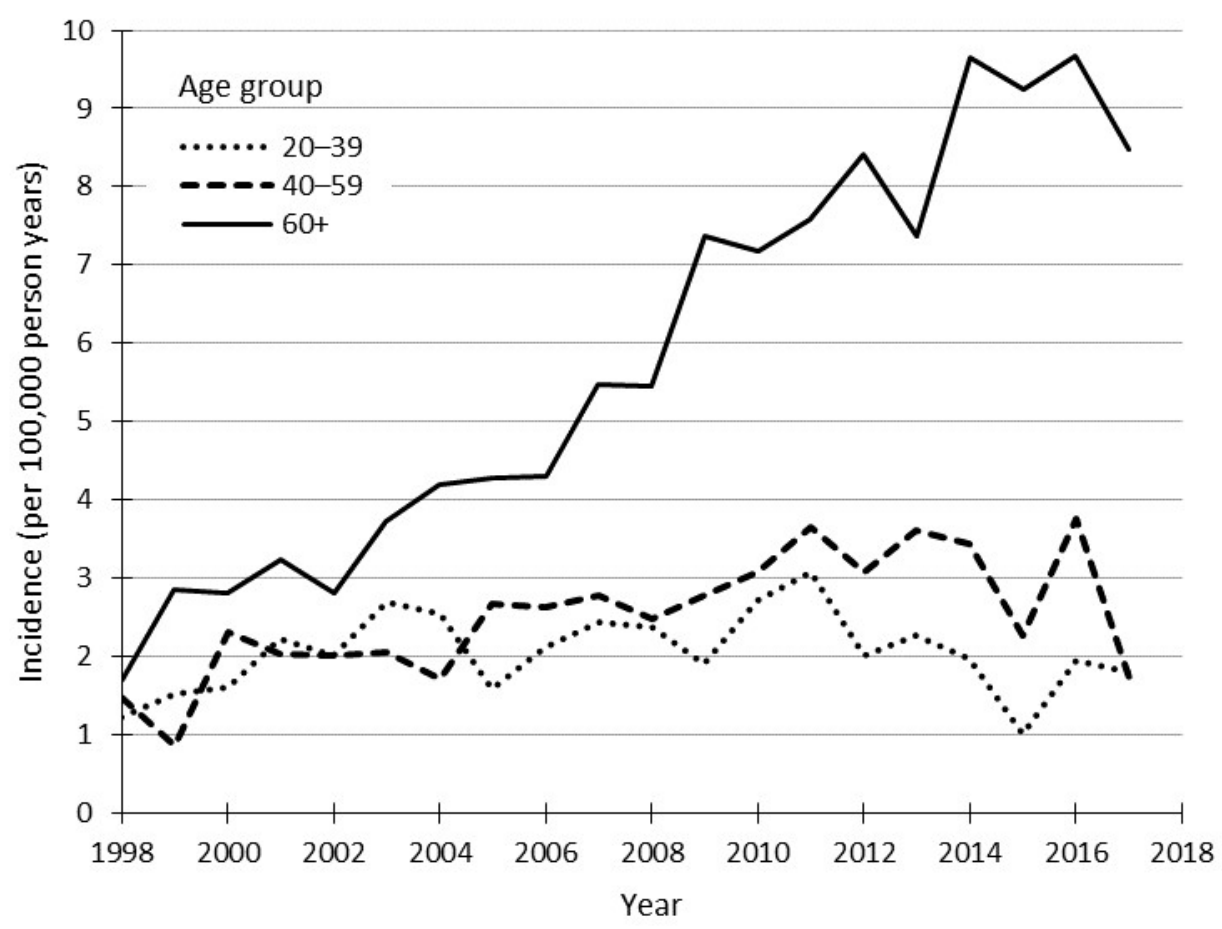

312 Figure 4. Incidence of cervical spine fracture surgery in Finland between 1998 and 2017.

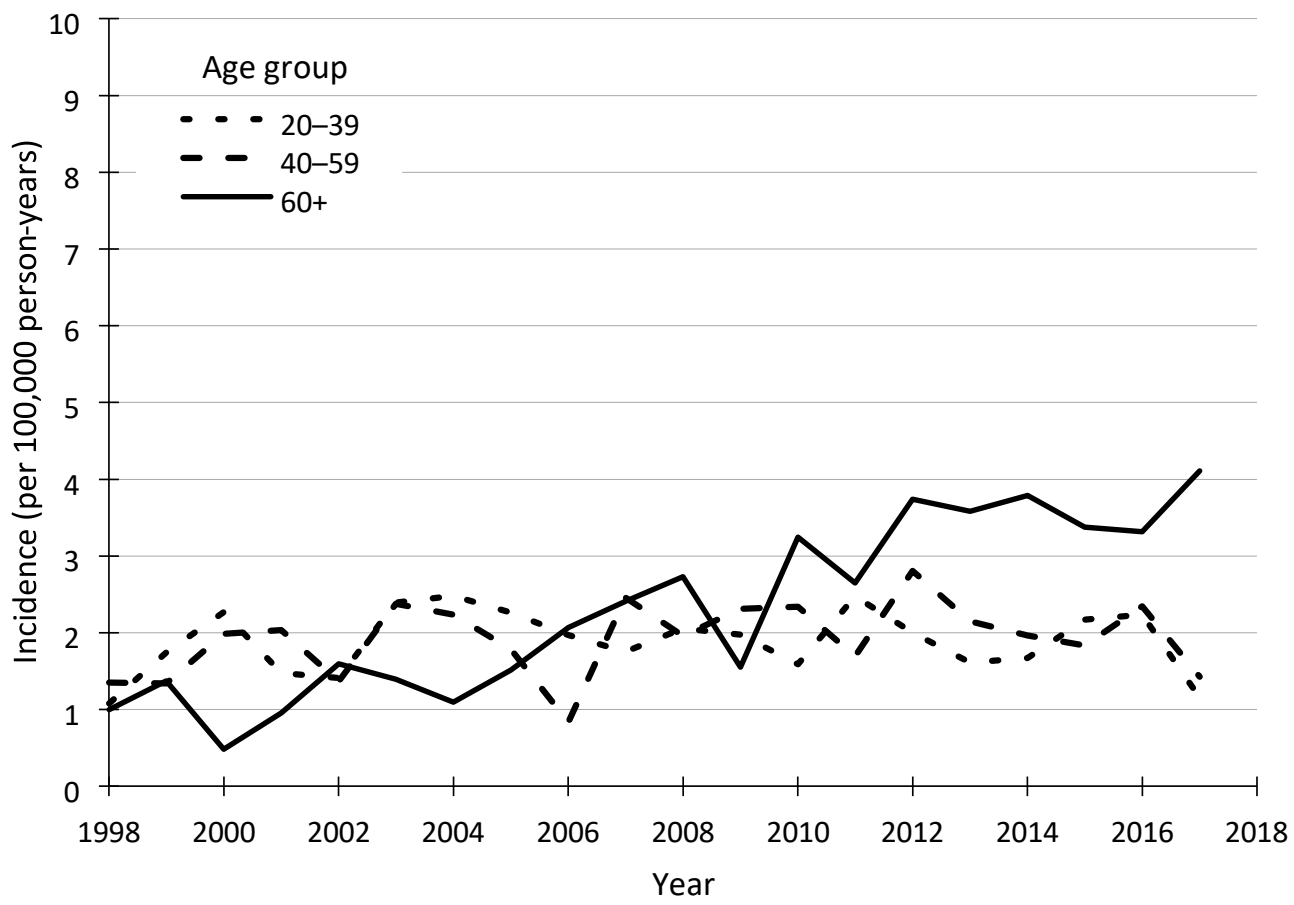

315 Figure 5. Incidence of thoracic spine fracture surgery in Finland between 1998 and 2017. 


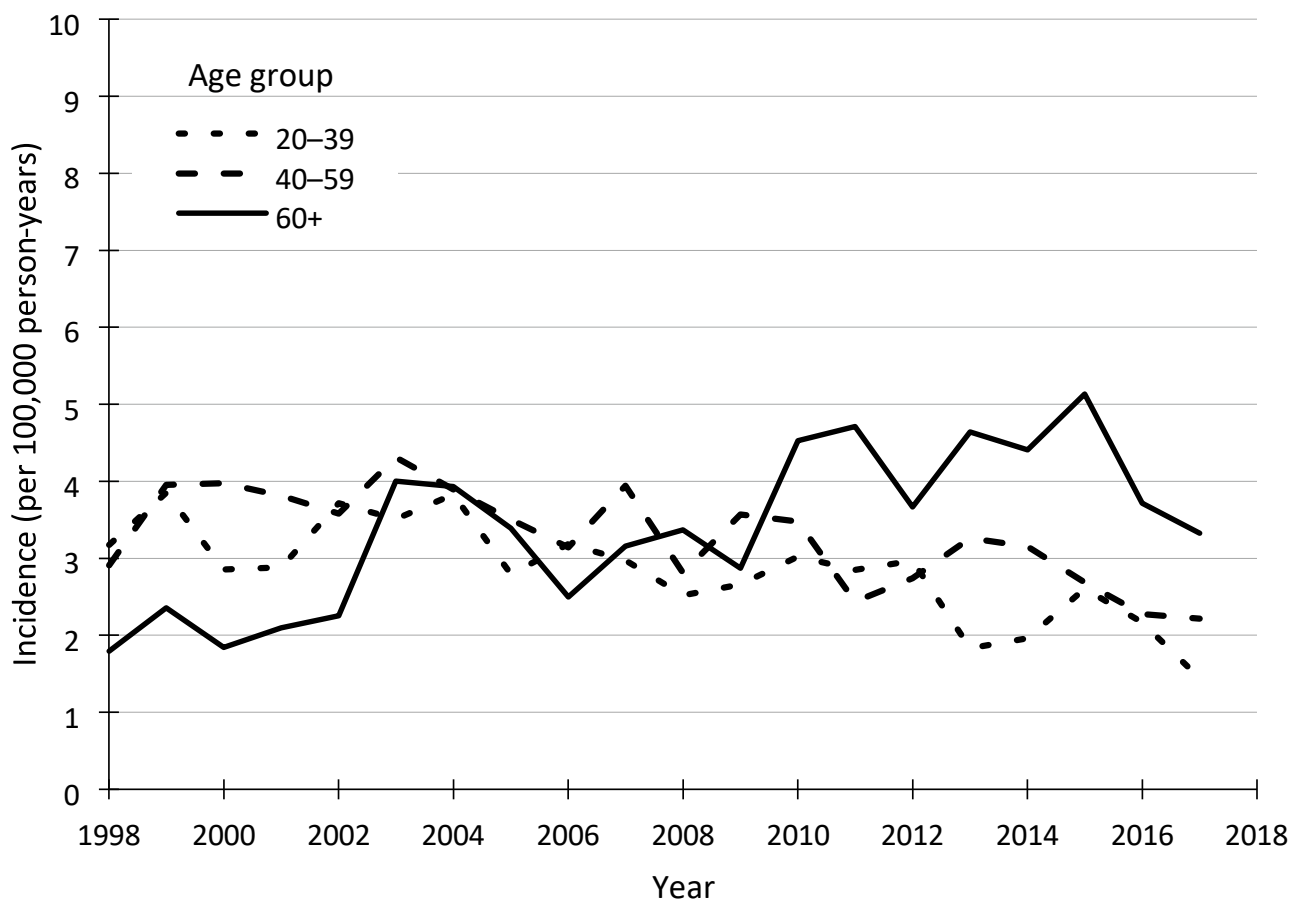

318 Figure 6. Incidence of lumbar spine fracture surgery in Finland between 1998 and 2017.

\section{References}

325

326

1.

Court-Brown CM, Caesar B. Epidemiology of adult fractures: A review.

Injury $327 \quad$ 2006;37:691-7.

$328 \quad 2 . \quad$ Oliver M, Inaba K, Tang A, et al. The changing epidemiology of spinal trauma: 13329 year review from a Level I trauma centre. Injury 2012;43:1296-300.

$330 \quad 3 . \quad$ Information CIfH, Federation CNS, Brain C, et al. The burden of neurological $331 \quad$ diseases, disorders and injuries in Canadaed: Canadian Neurological Sciences Federation= 332 Federation Des S, 2007.

$333 \quad$ 4. Niemi-Nikkola V, Saijets N, Ylipoussu H, et al. Traumatic spinal injuries in Northern $334 \quad$ Finland. Spine 2018;43:E45-E51.

$335 \quad 5 . \quad$ Somersalo A, Paloneva J, Kautiainen H, et al. Incidence of fractures requiring $336 \quad$ inpatient care. Acta orthopaedica 2014;85:525-30.

$337 \quad 6 . \quad$ Moradi-Lakeh M, Rasouli MR, Vaccaro AR, et al. Burden of traumatic spine fractures $338 \quad$ in Tehran, Iran. BMC public health 2011;11:789. 
$339 \quad$ 7. Hu R, Mustard CA, Burns C. Epidemiology of incident spinal fracture in a complete $340 \quad$ population. Spine 1996;21:492-9.

$341 \quad$ 8. Cosman F, Krege JH, Looker AC, et al. Spine fracture prevalence in a nationally representative sample of US women and men aged $\geq 40$ years: results from the National Health and 343 Nutrition Examination Survey (NHANES) 2013-2014. Osteoporosis International 2017;28:1857342 34466.

345 9. Cummings SR, Melton LJ. Epidemiology and outcomes of osteoporotic fractures. The 346 Lancet 2002;359:1761-7.

347 10. European Prospective Osteoporosis Study G, Felsenberg D, Silman AJ, et al.

348 Incidence of vertebral fracture in europe: results from the European Prospective Osteoporosis Study 349 (EPOS). J Bone Miner Res 2002;17:716-24.

350 11. Melton JLI. Epidemiology of Spinal Osteoporosis. Spine 1997;22:2S-11S.

351 12. Cooper C, O'Neill T, Silman A. The epidemiology of vertebral fractures. Bone 352 1993;14:89-97.

$353 \quad$ 13. Kröger H, Huopio J, Honkanen R, et al. Prediction of fracture risk using axial bone 354 mineral density in a perimenopausal population: a prospective study. Journal of bone and mineral 355 research 1995;10:302-6.

$356 \quad$ 14. Ross PD, Davis JW, Epstein RS, et al. Pre-existing fractures and bone mass predict 357 vertebral fracture incidence in women. Annals of internal medicine 1991;114:919-23.

358 15. Kattail D, Furlan JC, Fehlings MG. Epidemiology and clinical outcomes of acute 359 spine trauma and spinal cord injury: experience from a specialized spine trauma center in Canada in 
comparison with a large national registry. Journal of Trauma and Acute Care Surgery 2009;67:93643.

16. Oner C, Rajasekaran S, Chapman JR, et al. Spine Trauma-What Are the Current Controversies? Journal of orthopaedic trauma 2017;31:S1-S6.

17. Abudou M, Chen X, Kong X, et al. Surgical versus non-surgical treatment for thoracolumbar burst fractures without neurological deficit. Cochrane Database of Systematic Reviews 2013.

18. Korhonen N, Kannus P, Niemi S, et al. Rapid increase in fall-induced cervical spine injuries among older Finnish adults between 1970 and 2011. Age and ageing 2014;43:567-71.

19. Kannus P, Palvanen M, Niemi S, et al. Alarming rise in the number and incidence of fall-induced cervical spine injuries among older adults. The Journals of Gerontology Series A: Biological Sciences and Medical Sciences 2007;62:180-3.

20. Kannus P, Niemi S, Palvanen M, et al. Continuously increasing number and incidence of fall-induced, fracture-associated, spinal cord injuries in elderly persons. Archives of internal medicine 2000;160:2145-9.

21. Sund R. Quality of the Finnish Hospital Discharge Register: A systematic review. Scandinavian Journal of Public Health 2012;40:505-15.

22. Mattila VM, Sillanpaa P, Iivonen T, et al. Coverage and accuracy of diagnosis of cruciate ligament injury in the Finnish National Hospital Discharge Register. Injury 2008;39:13736.

23. Keskimaki I. Accuracy of data on diagnosis, procedures and accidents in the Finnish hospital register. Int J Health Sci 1991;2:15-21.

24. Brolin K. Neck injuries among the elderly in Sweden. Injury control and safety promotion 2003;10:155-64.

25. Devivo M. Epidemiology of traumatic spinal cord injury: trends and future implications. Spinal cord 2012;50:365.

26. Knutsdottir S, Thorisdottir H, Sigvaldason K, et al. Epidemiology of traumatic spinal cord injuries in Iceland from 1975 to 2009. Spinal cord 2012;50:123.

27. Jansson K-Å, Blomqvist P, Svedmark P, et al. Thoracolumbar vertebral fractures in Sweden: an analysis of 13,496 patients admitted to hospital. European journal of epidemiology 2010;25:431-7.

28. Huttunen TT, Launonen AP, Pihlajamäki H, et al. Trends in the surgical treatment of proximal humeral fractures - a nationwide 23-year study in Finland. BMC Musculoskeletal Disorders 2012;13:261. 
29. Huttunen TT, Kannus P, Lepola V, et al. Surgical treatment of humeral-shaft fractures: A register-based study in Finland between 1987 and 2009. Injury 2012;43:1704-8.

30. Mattila VM, Huttunen TT, Sillanpää P, et al. Significant change in the surgical treatment of distal radius fractures: a nationwide study between 1998 and 2008 in Finland. Journal of Trauma and Acute Care Surgery 2011;71:939-43.

31. Raittio LT, Jokihaara J, Huttunen TT, et al. Rising incidence of scaphoid fracture surgery in Finland. Journal of Hand Surgery (European Volume) 2018;43:402-6.

32. Huttunen TT, Launonen AP, Berg HE, et al. Trends in the incidence of clavicle fractures and surgical repair in Sweden: 2001-2012. JBJS 2016;98:1837-42.

33. Caron T, Bransford R, Nguyen Q, et al. Spine fractures in patients with ankylosing spinal disorders. Spine 2010;35:E458-E64.

34. Westerveld L, Verlaan J, Oner F. Spinal fractures in patients with ankylosing spinal disorders: a systematic review of the literature on treatment, neurological status and complications. European Spine Journal 2009;18:145-56.

35. Feldtkeller E, Vosse D, Geusens P, et al. Prevalence and annual incidence of vertebral fractures in patients with ankylosing spondylitis. Rheumatology international 2006;26:234-9.

36. Weinfeld RM, Olson PN, Maki DD, et al. The prevalence of diffuse idiopathic skeletal hyperostosis (DISH) in two large American Midwest metropolitan hospital populations. Skeletal radiology 1997;26:222-5.

37. Kagotani R, Yoshida M, Muraki S, et al. Prevalence of diffuse idiopathic skeletal hyperostosis (DISH) of the whole spine and its association with lumbar spondylosis and knee osteoarthritis: the ROAD study. Journal of bone and mineral metabolism 2015;33:221-9. 